\title{
Respiratory effort perception at rest and during carbon dioxide rebreathing in patients with dystrophia myotonica
}

John E Clague, Julie Carter, John Coakley, Richard H T Edwards, Peter M A Calverley

\begin{abstract}
Background - Breathlessness appears to be closely related to the perception of the outgoing motor command to breathe and should be increased in the presence of muscle weakness. However, breathlessness is not a common symptom in patients with chronic muscle disease who have weak respiratory muscles. The factors that determine the perception of respiratory effort in such patients have not been examined.
\end{abstract}

Methods - The inspiratory effort sensation during resting breathing and progressive hypercapnia was investigated in 12 patients with dystrophia myotonica with weak respiratory muscles (nine men and three women of mean (SD) age $41 \cdot 1$ $(\mathbf{1 0} .5)$ years; maximum inspiratory pressure $\left.43 \cdot 1(17 \cdot 2) \mathrm{cm} \mathrm{H}_{2} \mathrm{O}\right)$ and an age and sex matched control group of normal subjects of mean age $39.6(10.6)$ years and a maximum inspiratory pressure of 123 $(15 \cdot 2) \mathrm{cm} \mathrm{H}_{2} \mathrm{O}$.

Results - During resting breathing with a mouthpiece no differences were seen in inspiratory effort sensation, mouth occlusion pressure, or tidal volume, but inspiratory time and cycle duration were significantly shorter in the patients with dystrophia. Minute ventilation ( $\dot{V} E)$ was significantly higher in the patients $(15.8$ $(4 \cdot 0) 1 / \mathrm{min} v 12.5(2.6) 1 / \mathrm{min})$, while resting breathing was no more variable in the patients than in controls. The ventilatory response to carbon dioxide $\left(\dot{\mathrm{VE}} / \mathrm{PCO}_{2}\right)$ was not significantly lower in the patients $(14.9(6.9) 1 / \mathrm{min} / \mathrm{kPa})$ than in the controls $(17 \cdot 4(4 \cdot 3) 1 / \mathrm{min} / \mathrm{kPa})$. Effort sensation responses to carbon dioxide driven breathing were similar in the control subjects and the patients. With regression analysis of pooled data neither maximum inspiratory pressure nor disease state contributed to perceived inspiratory effort during hypercapnia.

Conclusions - Moderately severe global respiratory muscle weakness does not appear to influence the ventilatory response to rising carbon dioxide tension or the perception of inspiratory effort in patients with dystrophia myotonica.

(Thorax 1994;49:240-244)

The sensation of breathlessness occurs in many situations and its character varies with the clinical setting. ${ }^{1}$ The mechanism underlying this sensation remains disputed ${ }^{2}$ but has been equated with an increased sense of effort. $^{34}$ The sense of effort is believed to be the conscious awareness of the outgoing motor command to breathe and it has been proposed as a possible unitary explanation of breathlessness. The sense of inspiratory effort should increase when ventilation or the velocity of inspiratory muscle contraction increases, when the respiratory system impedance is high, or in the presence of muscle weakness. Inspiratory effort sensation increases when a large percentage of the static maximum pleural pressure is developed by normal subjects. ${ }^{5}$ In studies with acute inspiratory loading, the maximum inspiratory pressure is an important determinant of the severity of breathlessness. ${ }^{6}$ However, breathlessness is not a prominent complaint of patients with chronic muscle disease with generalised respiratory muscle weakness. One explanation may be that these patients cannot exercise enough to increase their ventilation to a point where breathlessness occurs. Alternatively there may be a defect in sensory perception, or temporal adaptation of respiratory sensation might occur in these chronically weak patients.

Respiratory sensation has not been systematically examined in patients with respiratory muscle disease. In this study we have examined respiratory sensation in a group of patients with dystrophia myotonica. This is an autosomal dominant disorder producing significant sternomastoid and facial weakness together with less marked but slowly progressive limb weakness. ${ }^{7}$ Variable respiratory muscle weakness occurs and respiratory complications such as hypersensitivity to anaesthetic agents and respiratory failure due to alveolar hypoventilation have been reported. ${ }^{8-11}$

In this study we wished to determine whether the perception of respiratory effort was normal in patients with dystrophia myotonica, and whether this was related to the degree of respiratory muscle weakness. As exercise is not always feasible in patients with muscle weakness, carbon dioxide rebreathing was used as a standard stimulus to increase inspiratory effort in a carefully characterised group of patients with dystrophia myotonica and a group of age and sex matched normal controls. In addition to measuring the ventilatory response to carbon dioxide we measured the mouth occlusion pressure response to car- 
bon dioxide as a more direct measure of respiratory centre output which is uninfluenced by the changes in pulmonary mechanics that occur with chronic respiratory muscle weakness. Effort sensation during resting breathing and resting breathing pattern were also assessed, as resting breathing pattern has been reported to be abnormal in patients with dystrophia myotonica. ${ }^{10-12}$

\section{Methods}

SUBJECTS

Twelve patients with clinical, electromyographic, and histologically diagnosed dystrophia myotonica who were attending a muscle clinic were studied. All were mobile without aid, two were working, and none complained of excessive daytime sleepiness or orofacial muscle weakness sufficient to impair respiratory measurements. All were able to sit without support and no patient had scoliosis. With the use of a disability grade ${ }^{12}$ three subjects were only mildly disabled (grade 1) and nine were moderately disabled (grade 2). No patients were severely disabled (grade 3 ) or bedbound (grade 4). No patient had radiographic evidence of diaphragmatic paralysis. A sex and age matched control group of normal subjects was also studied. Group mean (SD) data are given in table 1 . The study protocol was approved by our hospital ethical committee and all subjects gave their informed consent.

\section{STUDY DESIGN}

Subjects attended on two occasions and all measurements were made while seated. Spirometric measurements $\left(\mathrm{FEV}_{1}\right.$ and $\mathrm{FVC}$ ) were recorded with a dry bellows spirometer (Vitalograph Ltd), and static maximum mouth pressures were measured with a pressure transducer (Validyne MP45) using the technique of Black and Hyatt. ${ }^{13}$ The mean result of the three best recordings from five made after adequate training was used. Particular care was taken to avoid mouth leaks by supporting the cheeks of the patients. Arterial blood gas tensions were measured in the patients at rest breathing air and were analysed by an automatic blood gas analyser (Instrumentation Laboratories IL 213).

Resting breathing measurements were made with the subject seated wearing a noseclip and breathing through a mouthpiece from a low resistance two way valve (Hans Rudolph

Table 1 Mean (SD) group data for controls and patients with dystrophia myotonica

\begin{tabular}{|c|c|c|c|}
\hline & Controls & $\begin{array}{l}\text { Patients with dystrophia } \\
\text { myotonica }\end{array}$ & $p$ \\
\hline $\operatorname{Sex}(M: F)$ & $9: 3$ & $9: 3$ & \\
\hline Age (years) & $39 \cdot 6(10 \cdot 6)$ & $41 \cdot 1(10 \cdot 5)$ & NS \\
\hline Height $(m)$ & $1.76(0.07)$ & $1.73(0.08)$ & NS \\
\hline Weight (kg) & $71 \cdot 2(9 \cdot 7)$ & $70(15 \cdot 4)$ & NS \\
\hline FVC (1) & $4.91(1.1)$ & $3 \cdot 14(1 \cdot 21)$ & $<0.01$ \\
\hline FVC ( $\%$ predicted $)$ & $104(145)$ & $70 \cdot 2(19 \cdot 3)$ & $<0.01$ \\
\hline $\operatorname{MIP}\left(\mathrm{cm} \mathrm{H}_{2} \mathrm{O}\right)$ & $123(15 \cdot 2)$ & $43 \cdot 1(17 \cdot 2)$ & $<0.01$ \\
\hline MIP ( $\%$ predicted) & $108(17 \cdot 3)$ & $41 \cdot 3(17 \cdot 3)$ & $<0.01$ \\
\hline $\mathrm{PaCO}_{2}(\mathrm{kPa})$ & - & $5 \cdot 6(0.7)$ & \\
\hline Resting $\mathrm{SaO}_{2}(\%)$ & $98(1)$ & $97(1)$ & NS \\
\hline
\end{tabular}

$\mathrm{FVC}=$ forced vital capacity; $\mathrm{MIP}=$ maximum inspiratory pressure; $\mathrm{PaCO}_{2}=$ arterial carbon dioxide tension; $\mathrm{SaO}_{2}=$ arterial oxygen saturation; $\mathrm{NS}=$ not statistically significant.
2600). Airflow was measured with the use of a heated pneumotachograph (Fleisch No. 2) in the main circuit, and the integrated volume signal was recorded onto a strip chart recorder (Gould 2000 series). Tidal volume (VT) and respiratory frequency were measured, and minute ventilation ( $\dot{\mathrm{VE}})$, inspiratory time $(\mathrm{TI})$, total breathing cycle duration (ТTOT), mean inspiratory flow $(\mathrm{VT} / \mathrm{TI})$, and duty cycle $\left(\mathrm{TI}_{\mathrm{I}}\right.$ Ттот) were calculated. Mouth pressure was measured at the mouthpiece with a separate pressure transducer (Gould P23XL). From this signal mouth occlusion pressure was measured after airway occlusion by a manually operated helium balloon valve (Hans Rudolph 9300) occluded in expiration and recorded onto the chart recorder $100 \mathrm{~ms}$ after airway occlusion was determined from the trace. One to two breaths before each airway occlusion the subject was asked "How difficult is it to breathe?" and the response was recorded on the modified Borg scale. ${ }^{14}$ Occlusion pressure measurements and effort sensation scores were recorded at 30 second intervals during resting breathing. End tidal carbon dioxide tension $\left(\right.$ PETCO $\left._{2}\right)$ was measured continuously with a fast response infrared carbon dioxide analyser (Gambro Engstrom).

Ventilatory responses to carbon dioxide were measured by a rebreathing technique with initial gas concentrations of $6 \%$ carbon dioxide and $94 \%$ oxygen. The circuit consisted of a reservoir bag (six litres) in a sealed box with inspiratory and expiratory connections to the two way valve used during resting breathing. Minute ventilation ( $\mathrm{VE}$ ) was measured by air displacement from the box through a turbine spirometer and carbon dioxide tension by a fast response infrared carbon dioxide analyser ( $P K$ Morgan Ltd). Mouth occlusion pressure and inspiratory effort sensation were measured at 30 second intervals (the same as during resting breathing) throughout each rebreathing run, which lasted 3.5 minutes.

Resting breathing data were recorded on each occasion for three minutes. Recordings were taken after allowing five minutes for breathing pattern and PETCO $_{2}$ to stabilise. Control subjects and patients also attempted resting breathing with an inspiratory resistive load of $10 \mathrm{~cm} \mathrm{H} \mathrm{H}_{2} \mathrm{O}$ in the breathing circuit. Resting breathing and hypercapnic responses were performed in duplicate on separate days. At least one training run was performed before data were collected to reduce initial overscoring. ${ }^{15}$ Subjects wore headphones playing music to mask external sounds.

\section{DATA ANALYSIS}

Mean values for inspiratory effort sensation, mouth occlusion pressure, TI, TтоT, VT, and $\mathrm{PETCO}_{2}$ during resting breathing were determined for each subject. Mean values of $\mathrm{VT} / \mathrm{TI}$, $\dot{V E}$, and respiratory frequency were calculated. The variability of TTOT was determined by measuring the coefficient of variation of TTOT for all breaths in the three minute recording. Comparisons of the mean resting breathing 
Table 2 Mean (SD) group resting breathing pattern data

\begin{tabular}{|c|c|c|c|}
\hline & Controls & $\begin{array}{l}\text { Patients with dystrophia } \\
\text { myotonica }\end{array}$ & $p$ \\
\hline $\begin{array}{l}\text { IES (units) } \\
P_{0.1}\left(\mathrm{~cm} \mathrm{H} \mathrm{H}_{2} \mathrm{O}\right) \\
\operatorname{TI}(\mathrm{s}) \\
\text { TTOT (s) } \\
\text { TI/TTOT } \\
\text { VT (l) } \\
\text { VT } / \mathrm{TI}(\mathrm{l} / \mathrm{s}) \\
\text { f }(\mathrm{bpm}) \\
\dot{\mathrm{VE}}(\mathrm{l} / \mathrm{min}) \\
\operatorname{PETCO}_{2}(\mathrm{kPa})\end{array}$ & $\begin{array}{c}0.35(0.58) \\
1.67(0.7) \\
1.75(0.5) \\
4.73(1.3) \\
0.37(0.05) \\
0.96(0.2) \\
0.58(0.14) \\
13.6(3.9) \\
12.5(2.6) \\
5.3(0.5)\end{array}$ & $\begin{array}{c}0.74(0.9) \\
1.55(0.72) \\
1.43(0.37) \\
3.44(0.79) \\
0.42(0.07) \\
0.88(0.18) \\
0.65(0.14) \\
18.3(4.7) \\
15.8(4.0) \\
5.1(0.7)\end{array}$ & $\begin{array}{l}\text { NS } \\
\text { NS } \\
<0.05 \\
<0.01 \\
<0.05 \\
\text { NS } \\
\text { NS } \\
<0.01 \\
<0.05 \\
\text { NS }\end{array}$ \\
\hline
\end{tabular}

IES = inspiratory effort sensation; $P_{0.1}=$ month occlusion pressure; $\mathrm{T}_{\mathrm{I}}=$ inspiratory time; TTOT $=$ respiratory cycle time; $\mathrm{TI} / \mathrm{TTOT}=$ duty cycle; $\mathrm{VT}=$ tidal volume; $\mathrm{VT} / \mathrm{TI}=$ mean inspiratory flow; $f=$ frequency; $\dot{V E}=$ minute ventilation; $\mathrm{PETCO}_{2}=$ end tidal carbon dioxide tension; $\mathrm{NS}=$ not statistically significant.

\author{
Individual variability of \\ TTOT during resting \\ breathing. $N=$ normal, \\ DM= dystrophia \\ myotonica.
}

data were made between patients and control subjects with the Wilcoxon signed rank test. ${ }^{15}$

The relations between minute $\dot{V} E$ and carbon dioxide tension, inspiratory effort sensation and carbon dioxide tension, $\mathbf{V E}$ and mouth occlusion pressure, and mouth occlusion pressure and carbon dioxide tension during rebreathing were calculated by linear regression with the least squares method using data points at 30 second intervals. Statistical analyses of the mean calculated slopes were performed with the Wilcoxon signed rank test. ${ }^{16}$ All data are expressed as mean (SD) unless otherwise stated.

To maximise the data available for analysis, multiple linear regression analysis ${ }^{16}$ was applied to the pooled data from normal subjects and patients with dytrophia myotonica (DM). We considered the effects of disease, respiratory muscle weakness and respiratory impedance

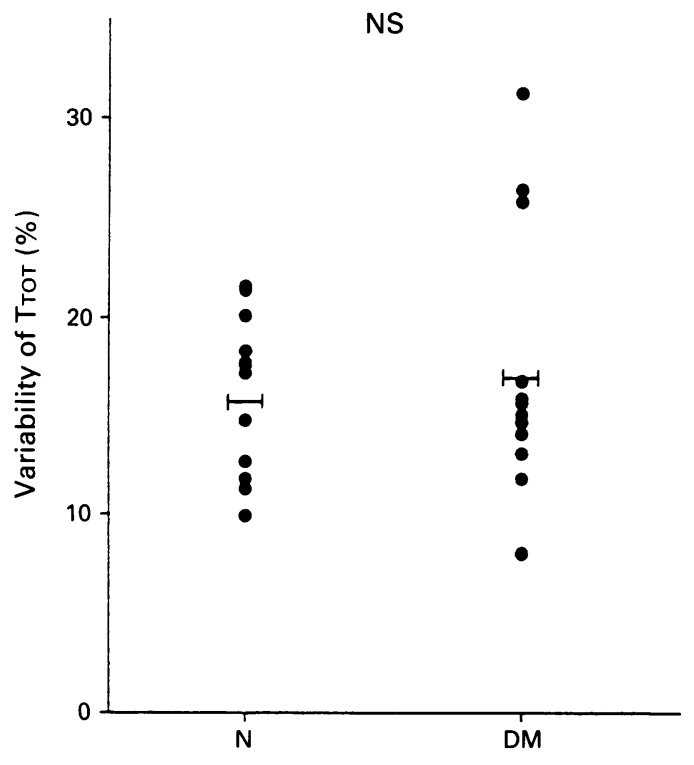

Table 3 Mean (SD) group results following carbon dioxide rebreathing

\begin{tabular}{|c|c|c|c|}
\hline & Controls & $\begin{array}{l}\text { Patients with dystrophia } \\
\text { myotonica }\end{array}$ & $p$ \\
\hline 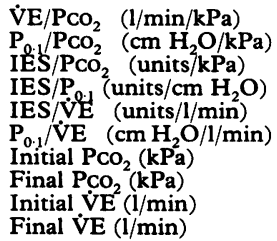 & $\begin{array}{l}17.4(4.3) \\
2.96(1.1) \\
1.85(0.6) \\
0.63(0.24) \\
0.13(0.06) \\
0.19(0.09) \\
6.32(0.46) \\
8.48(0.47) \\
15.9(4.9) \\
55(15.9)\end{array}$ & $\begin{array}{l}14.9(6.9) \\
2 \cdot 24(1.0) \\
2.4(1.9) \\
0.96(0.35) \\
0 \cdot 16(0.06) \\
0.16(0.06) \\
6.34(0.36) \\
8.41(0.67) \\
17.6(4.6) \\
48.3(16.3)\end{array}$ & $\begin{array}{l}\text { NS } \\
\text { NS } \\
\text { NS } \\
\text { NS } \\
\text { NS } \\
\text { NS } \\
\text { NS } \\
\text { NS } \\
\text { NS } \\
\text { NS }\end{array}$ \\
\hline
\end{tabular}

$\dot{\mathrm{V} E}=$ minute ventilation; $\mathrm{PCO}_{2}=$ carbon dioxide tension; $\mathrm{P}_{0.1}=$ mouth occlusion pressure IES $=$ inspiratory effort sensation; NS $=$ not statistically significant. (measured as $\mathrm{P}_{0.1} / \dot{\mathrm{V} E}$ derived by dividing mouth occlusion pressure $\left(\mathbf{P}_{0.1}\right)$ by $\dot{V} E$ at each time point) on the relation between the stimulus $\left(\mathrm{PCO}_{2}\right)$ and inspiratory effort sensation (IES) using the following equations:

$$
\begin{gathered}
\text { IES }=a+b\left(\mathrm{PCO}_{2}\right)+c(\text { normal or } \mathrm{DM}) \\
\text { IES }=\mathrm{a}+\mathrm{b}\left(\mathrm{PCO}_{2}\right)+\mathrm{d}(\mathrm{MIP})+\mathrm{c}(\text { normal or } \mathrm{DM}) \\
\text { IES }=\mathrm{a}+\mathrm{e}(\dot{\mathrm{VE}})+\mathrm{d}(\mathrm{MIP})+\mathrm{f}\left(\mathbf{P}_{0.1} / \mathrm{VE}\right)
\end{gathered}
$$

where $\mathrm{c}$ is a categorical variable assigned as $0=$ normal, $1=\mathrm{DM}$, and $\mathrm{MIP}=$ maximum inspiratory pressure. Total sums of squares and partial $\mathrm{F}$ values were calculated.

\section{Results}

\section{BREATHING AT REST}

Summary data describing spirometric parameters and maximum inspiratory pressures are shown in table 1 . Only one patient had a $\mathrm{PaCO}_{2}$ greater than $6 \mathrm{kPa}$. Respiratory muscle weakness as assessed by measurements of maximum inspiratory pressure was variable, but was not well reflected by a reduced vital capacity in the patients with dystrophia.

Mean resting breathing pattern data are presented in table 2 . Under isocapnic unloaded conditions there were no differences in inspiratory effort sensation, mouth occlusion pressure, $\mathrm{PETCO}_{2}$ or VT between patients and controls. Both TI and TTOT were reduced in the patients and the latter accounted for the higher respiratory frequency and the higher $\mathrm{VE}$ than in the normal subjects. Breath to breath variability in Ттот, a measure of ventilatory control, was similar in both groups (figure).

All the normal subjects tolerated the resistive load during resting breathing, but no patient was able to do so. Some patients were unable to breathe at all with the resistor in place, while others gave up before a stable breathing pattern could be established. No data are therefore presented on loaded breathing.

\section{$\mathrm{CO}_{2}$ REBREATHING}

Individual linear regression analyses between $\dot{V} E$, carbon dioxide tension, mouth occlusion pressure, and inspiratory effort sensation were highly intercorrelated in all the normal subjects and patients (all $r$ values $>0.9$ ). Group mean results are given in table 3 . Ventilatory responses $\left(\dot{\mathrm{VE}} / \mathrm{PCO}_{2}\right)$ and occlusion pressure $\left(\mathbf{P}_{0.1} / \mathbf{P C O}_{2}\right)$ responses were lower in the patient group, although not significantly so. Similarly, there were no differences between the occlusion pressure/litre of ventilation $\left(\mathrm{P}_{0 \cdot 1} / \mathrm{VE}\right)$ slopes, a measure of respiratory impedance, between the two groups, nor was there any significant difference in the rate of increase of effort sensation with increasing $\mathrm{PCO}_{2}$. This was true whether inspiratory effort sensation was related to $\mathrm{PCO}_{2}, \dot{\mathrm{VE}}$, or occlusion pressure, and was not explained by differences in the initial or final levels of $\mathrm{PCO}_{2}$ or $\dot{\mathrm{VE}}$ during the rebreathing (table 3 ). 
No correlation was found between resting arterial carbon dioxide tension and the ventilatory or occlusion pressure responses to carbon dioxide in patients with dystrophia myotonica. No relation was found between age and effort sensation responses to carbon dioxide, nor between age and ventilatory and occlusion pressure responses to carbon dioxide.

\section{FACTORS INFLUENCING INSPIRATORY EFFORT SENSATION}

In equations 1 and 2 effort sensation (IES) was related only to the stimulus $\left(\mathrm{PCO}_{2}\right)$ and was not influenced by either disease state or maximum inspiratory pressure (MIP). When the stimulus to inspiratory effort sensation was considered in mechanical terms (equation 3 ) it was principally determined by $\dot{\mathrm{VE}}(\mathrm{F}=59 \cdot 2$, $\mathrm{p}<0.0001)$, impedance $\left(\mathrm{P}_{0.1} / \mathrm{VE}, \mathrm{F}=22 \cdot 1\right.$, $\mathrm{p}<0.0001$ ) with MIP making a smaller independent contribution $(\mathrm{F}=11.5, \mathrm{p}<0.001)$.

\section{Discussion}

Dystrophia myotonica is a well characterised cause of muscle weakness without major abnormality in respiratory mechanics. Our results suggest that this weakness does not reduce the ventilatory response to carbon dioxide and is not an important determinant of respiratory sensation when respiratory impedance is normal.

We assessed resting ventilation using a mouthpiece and noseclip. This method yields higher values during uninstrumented recordings, mainly because of an increase in inspiratory flow. ${ }^{17}$ Such problems were common to both our study groups, but the minute ventilation of our control subjects was close to that seen in other studies, ${ }^{18}$ and higher than those reported by Serisier et al. ${ }^{10}$ As reported by other studies, ${ }^{1019}$ our patients with dystrophia myotonica had a rapid breathing pattern but they did not generate a higher mouth occlusion pressure or experience greater resting inspiratory effort sensation to produce this. The relatively regular breathing pattern seen in both groups may reflect the stimulant effect of an added dead space.

Previous studies have suggested that the ventilatory response to carbon dioxide is depressed in patients with dystrophia myoton$\mathrm{ica}^{10}$ which might predispose to carbon dioxide retention, or reflect inspiratory muscle weakness, or both. ${ }^{12}$ We found no differences in the ventilatory, occlusion pressure, or effort sensation responses of our groups, nor were the $\mathrm{P}_{0.1} /$ $\mathrm{PCO}_{2}$ slopes disproportionately elevated in the patients as has been suggested previously. ${ }^{19}$

Respiratory sensation during carbon dioxide stimulated breathing has not been reported previously in patients with isolated respiratory muscle weakness. In our patients without respiratory symptoms we saw no evidence of increased sensory scoring at rest or during carbon dioxide stimulated increases in ventilation. Multiple regression analyses of the pooled data confirmed that neither disease category nor maximum inspiratory pressure influenced inspiratory effort sensation, and only when considered in mechanical terms did muscle weakness, as represented by lower maximum inspiratory pressure, make a small contribution to effort sensation.

There are several possible explanations for these findings. Patients with dystrophia myotonica may systematically mis-score their sensory responses, but this seems unlikely. Sensory adaptation might occur in the patients, but no correlation was found between age - and hence disease duration - and effort sensation responses. There may be a defect in the muscle spindles or a failure of central nervous system processing in patients with dystrophia myotonica which reduces their perception of muscle weakness and leads to an inappropriately low effort sensation for a given level of muscle activation. The inability of our patients to tolerate a small inspiratory resistive load makes this explanation and sensory adaptation unlikely.

Alternatively, effort perception may rise only when the additional impedance requires a greater degree of muscle activation to produce the same volume change. This would explain the results of equation 3 where inspiratory effort sensation increased when $P_{0.1} / \dot{V E}$ was increased. This was the only circumstance where maximum inspiratory pressure explained some of the variance of inspiratory effort sensation, presumably because weak muscles require a greater degree of activation to produce the same pressure. Even here changes in $\mathrm{P}_{0.1} / \dot{\mathrm{VE}}$ or maximum inspiratory pressure would have to be large, as the principal determinant of inspiratory effort sensation was VE.

The limited role for maximum inspiratory pressure as a predictor of respiratory sensation is in keeping with data from thyrotoxic patients whose respiratory muscle function improved after treatment, but whose breathlessness scoring remained unaltered. ${ }^{20}$ The quality of the sensation perceived differs with the stimulus, at least in normal subjects, ${ }^{21}$ and these differences may reflect changes in the relative importance of impedance, maximum inspiratory pressure, and ventilatory components of respiratory sensation.

These results emphasise that significant respiratory muscle weakness can be present in the absence of clinical symptoms and without the patient perceiving changes in unloaded ventilation as being abnormal. In our patients breathing pattern rather than ventilatory control was the most consistent abnormality, and respiratory effort perception was unrelated to the degree of respiratory muscle weakness. When respiratory impedance is increased, however, the scope for load compensation may be more restricted, and carbon dioxide retention and symptoms may rapidly develop when there is a background of respiratory muscle weakness. Assessment of static maximum mouth pressure may be of predictive value in these circumstances.

1 Elliott MW, Adams L, Cockcroft A, Macrae KD, Murphy $\mathrm{K}$, Guz A. The language of breathlessness. Use of verbal 
descriptors by patients with cardiopulmonary disease. $\mathrm{Am}$ Rev Respir Dis 1991;144:826-32.

2 The enigma of breathlessness (editorial). Lancet 1986;i:9812 .

3 Killian KJ, Campbell EJM. Dyspnea. In: Roussos C, Macklem PT, eds. The thorax: Part B. Lung biology in
health and disease. New York: Marcel Dekker, 1985:787health

4 Killian KJ, Gandevia JC, Summers E, Campbell EJM. Effect of increased lung volume on perception of breathlessness, effort and tension. F Appl Physiol 1984;57:68691.

5 Bradley TD, Chartrand DA, Fitting JW, Killian KJ, Grassino A. The relation of inspiratory effort sensation to fatiguing patterns of the diaphragm. Am Rev Respir Dis 1986;134:1119-24

6 El-Manshawi A, Killian KJ, Summers E, Jones NL. Breathlessness and exercise with and without resistive loading. F Appl Physiol 1986;61:896-905.

7 Myotonic disorders. In: Walton JN, ed. Disorders of voluntary muscle. 5th edn. Edinburgh: Churchill Livingstone, 1988:569-87.

8 Kaufman L. Anaesthesia in dystrophia myotonica: a review of the hazards of anaesthesia. Proc $R$ Soc Med 1960;53:183-8.

9 Kilburn KH, Eagen JT, Sieker HO, Heyman A. Cardiopulmonary insufficiency in myotonic and progressive muscumonary insufficiency in myotonic and progressive
lar dystrophy. $N$ Engl $f$ Med 1959;261:1089-93.

10 Serisier DE, Mastaglia FL, Gibson GJ. Respiratory muscle function and ventilatory control. I In patients with motor neurone disease. II In patients with myotonic dystrophy. $Q \mathcal{F}$ Med 1982;51:205-26.
11 Carroll JE, Zwillich CW, Weil JV. Ventilatory response in myotonic dystrophy. Neurology 1977;27:1125-8.

12 Gillam PMS, Heaf PJD, Kaufman L, Lucas BGB. Respiration in dystrophia myotonica. Thorax 1964;19:11220.

13 Black LF, Hyatt RE. Maximum respiratory pressure: normal values and relationship to age and sex. Am Rev Respir Dis 1969;99:696-702.

14 Borg GAV. Psychophysical basis of perceived exertion. Med Sci Sports Exerc 1982;14:377-81.

15 Wilson RC, Jones PW. A comparison of the visual analogue scale and modified Borg scale for the measurement of dyspnoea during exercise. Clin Sci 1989;76:277-82.

16 Armitage P, Berry G. Statistical methods in medical research. 2nd edn. Oxford: Blackwell, 1987:408-21.

17 Askanazi J, Silverberg PA, Foster RJ, Hyman AI, MilicEmili J, Kinney JM. Effects of respiratory apparatus on breathing pattern. 7 Appl Physiol 1980;48:577-80.

18 Wiegand L, Zwillich CF, White DP. Sleep and the ventilatory response to resistive loading in normal men. $\mathcal{F} \mathrm{Appl}$ Physiol 1988;64:1186-95.

19 Begin R, Bureau MA, Lupien L, Lemieux B. Control and modulation of respiration in Steinert's myotonic dystrophy. Am Rev Respir Dis 1980;121:231-89.

20 McElvaney GN, Wilcox PG, Fairbairn MS, Hillian C, Wilkins GE, Pare PD, et al. Respiratory muscle weakness and dyspnea in thyrotoxic patients. Am Rev Respir Dis and dyspnea in thy

21 Simon P, Schwartzstein R, Weiss JW, Lattive K, Teghtsoonian $M$, Weinberger $S$. Distinguishable sensations of breathlessness induced in normal volunteers. Am Rev Respir Dis 1990;140:1021-7. 